\title{
FUNDAÇÃO ESCOLA TÉCNICA LIBERATO SALZANO VIEIRA DA CUNHA: DA CONSTRUÇÃO FÍSICA À CONSTITUIÇÃO DE UM MITO DE EXCELÊNCIA (1957-1967)
}

Deise Margô Müller ${ }^{1}$

Luciane Sgarbi S. Grazziotin ${ }^{2}$

\section{RESUMO}

Este estudo tem viés historiográfico e o objeto de análise é a Fundação Escola Técnica Liberato Salzano Vieira da Cunha localizada no município de Novo Hamburgo/RS. Tem o objetivo de explicitar as escolhas metodológicas que viabilizam a produção historiográfica vinculada à temática da História das Instituições de Ensino. Ao se investigar a gênese do processo de implantação de uma escola técnica, em determinado tempo e lugar, foi possível compreender a construção de um discurso de excelência de ensino em tal instituição e o envolvimento desse discurso com as políticas públicas de educação vigentes no período estudado, articuladas às características regionais do espaço geográfico em que a escola está localizada.

Palavras chave: Metodologia de Pesquisa. Ensino Técnico Profissionalizante. História da Educação. História das Instituições de Ensino.

\footnotetext{
${ }^{1}$ Doutora em Educação, pelo Programa de Pós-Graduação em Educação pela UNISINOS. Pesquisadora da linha de pesquisa -Educação, História e Política. Professora na Fundação Escola Técnica Liberato Salzano Vieira da Cunha. ORCID: http://orcid.org/0000-0001-5648-3855. ORCID: Email: deisemargo@gmail.com

2 Pós-doutorado em Educação. Professora do PPGEDU da Universidade do Vale do Rio dos Sinos - Unisinos. Líder do Grupo de pesquisa EBRAMIC- Educação no Brasil: memória, instituições e cultura escolar (CNPq). Participa do grupo de pesquisa Memórias e Histórias da escola do Rio Grande do Sul: Do Deutscher Hilfsverein ao Colégio Farroupilha (1858-2008), (CNPq). ORCID: http://orcid.org/0000-0002-9591-0183. E-mail: lusgarbi@terra.com.br
} 


\section{LIBERATO SALZANO VIEIRA DA CUNHA TECHNICAL SCHOOL: FROM THE PHYSICAL CONSTRUCTION TO THE CONSTITUTION OF A MYTH OF EXCELLENCE (1957-1967)}

\section{ABSTRACT}

This historiographical study relates to the History of Educational Institutions, and its object of analysis is the Liberato Salzano Vieira da Cunha Technical School, located in the city of Novo Hamburgo/RS. It aims at revealing the methodological choices that enable historiographical production in past times. Investigating the genesis of the process of implantation of a technical school, in a certain time and place, enabled understanding about the construction of a discourse of educational excellence in this institution, as well as the involvement of this discourse with educational public policies in effect in the period studied, articulated to the regional characteristics of the geographic space in which the school is located.

Keywords: Research Methodology. Technical Professional Secondary Education. History of Education. History of Educational Institutions.

\section{FUNDACIÓN ESCUELA TÉCNICA LIBERATO SALZANO VIEIRA DA CUNHA: DE LA CONSTRUCCIÓN FÍSICA HASTA LA CONSTITUCIÓN DE UN MITO DE EXCELENCIA (1957 - 1967)}

\section{RESUMEN}

Este estudio tiene un carácter historiográfico y el objeto del análisis es la Fundación Escuela Técnica Liberato Salzano Vieira da Cunha, situada en la ciudad de Novo Hamburgo/RS. Tiene el objetivo de explicitar las opciones metodológicas que hacen posible la producción historiográfica vinculada a la temática de la Historia de las Instituciones de Educación. Investigando el origen del proceso de implantación de una escuela técnica, en determinado tiempo y lugar, fue posible entender la construcción de un discurso de excelencia de enseñanza en tal institución y el envolvimiento de ese discurso con las políticas públicas de educación vigentes en el período estudiado, 
articuladas a las características regionales del espacio geográfico donde se localiza la escuela.

Palabras clave: Metodología de investigación. Enseñanza técnica profesional. Historia de la Educación. Historia de las Instituciones de Educación.

\section{INTRODUÇÃO}

Este estudo se vincula à temática da História das Instituições de Ensino, e seu objeto de análise é a Fundação Escola Técnica Liberato Salzano Vieira da Cunha $^{3}$ no que se refere às possibilidades de produção historiográfica de tal instituição. Com relação ao estudo das instituições escolares, Magalhães (2004) afirma que, "[...] na relação instituição/educação, a pedagogia institucional procura otimizar o encontro pedagógico, traduzindo-o por uma ou várias das seguintes acepções: lugar (espaço), tempo, fazer/dizer e ethos ${ }^{4 \prime \prime}$ (p. 65)

Em consonância com a afirmação de Magalhães, essa investigação se propõe a organizar uma gênese da Instituição, estabelecida em um recorte que tem as décadas de 1956 a 1967 como foco. Tem a intenção de compreender "o lugar", Fundação Liberato, como espaço físico em um determinado tempo, no qual ambos, espaço e tempo, estão relacionados à produção de um ethos construído ao longo de terminado período.

A Fundação Liberato, localizada no município de Novo Hamburgo, no estado do Rio Grande do Sul, Brasil, iniciou suas

\footnotetext{
${ }^{3}$ A instituição estudada, também denominada neste estudo de Fundação Liberato, é reconhecida, em sua comunidade escolar e também na localidade, por Fundação Liberato, ou por "a Liberato"; localiza-se no município de Novo Hamburgo. O artigo feminino utilizado para se referir à escola vem do fato de ser 'a' fundação e 'a' escola; portanto, no texto, serão por vezes utilizadas as duas denominações como referência à Instituição.

4 Neste artigo, não se tem a intenção de aprofundar nem discutir o conceito ethos, mas é importante explicitar que, aqui, entende-se por ethos os traços característicos de um grupo humano qualquer que o diferenciam de outros grupos, sob os pontos de vista social e cultural. Portanto, trata-se da identidade social de um grupo. Ethos significa o modo de ser, o caráter. (LENSKI, 1974).
} 
atividades em 1967. As tratativas para sua criação iniciaram em 1957, período de grande expansão industrial na região em que se situa; no entanto, sua inauguração nos remete ao ano de 1967.

Para compreender o processo de criação e o ethos construído sobre tal instituição, é fundamental certa imersão nas características regionais do espaço geográfico em que está localizada.

Novo Hamburgo é um município situado na região metropolitana de Porto Alegre, capital do Rio Grande do Sul. A história do lugar registra influência e contribuição da colonização germânica. Com a imigração, também houve o desenvolvimento da indústria local: o tratamento do couro e a produção do calçado conheceram, entre as décadas de 1950 e 1970, seu período áureo, quando ocorreu a implantação de uma legislação específica, que definia o ensino industrial como um dos ramos do sistema educacional.

As reformas e às mudanças nas maneiras de estruturar a escola, como um todo, ou seja, de conceber os currículos, de organizar as prioridades dos espaços de educação, de incentivar determinadas práticas e coibir outras são espaços de disputa e, em certa medida, são um reflexo das políticas de um país. Nesse sentido, as políticas de redefinição da estrutura do ensino secundário foi o caminho elegido pelo governo com objetivo de constituir uma mão de obra profissionalizada, a qual seria adequada ao novo cenário político, econômico e social que se definia no período.

O objetivo deste estudo é, portanto, estabelecer determinado percurso histórico de uma instituição escolar, atrelado aos interesses regionais e nacionais, de maneira a articular documentos históricos e itinerários metodológicos. Nesse processo, tem-se como finalidade compreender os distintos aspectos que permitiram a construção de um discurso de excelência de ensino. Para tal, o artigo explicita e discute os diferentes documentos selecionados para a produção historiográfica e as possibilidades metodológicas de analisá-los.

Ao buscar as primeiras fontes para entender as origens da Fundação Liberato, identificou-se a intenção de se construir uma escola técnica nas proximidades de Porto Alegre. Um convênio que uniu as três esferas da administração pública: União, Estado e Município, Essa articulação viabilizou a construção da escola em Novo 
Hamburgo, em 1957, fato suscitou alguns questionamentos iniciais. Se já havia o convênio em 1957, por que a Instituição foi inaugurada somente em 1967? Qual o contexto e quais os envolvidos nesse processo de construção? Como os movimentos sociopolíticos brasileiros da época influenciaram na construção? Por meio de que documentos seria possível construir um regime de historicidade que permitisse analisar a produção de um mito de excelência?

\section{A PRODUÇÃO HISTORIOGRÁFICA DE UMA INSTITUIÇÃO: ASPECTOS METODOLÓGICOS}

Discutem-se, nesta seção, elementos teóricos e metodológicos que possibilitaram a construção desta investigação; explicita-se, portanto, a base teórica tomada como referência, abordando-se os documentos selecionados e o modo como foram analisados.

Considera-se fundamental explicitar os percursos metodológicos dessa investigação, uma vez que são as opções por determinados caminhos, e não outros, que visibilizam e dão coerência aos resultados encontrados. Nesse sentido, Veyne (2014) afirma que são os conteúdos de nossas experiências que nos permitem preencher as lacunas da história em uma arte que é capaz de expressar tempos anteriores. Entende-se que o autor esteja considerando que são nossas opções teóricas e metodológicas, os caminhos elegidos e, sobretudo, as experiências pessoais que nos permitem construir uma história e não outra. Os teóricos da historiografia contemporânea expressam preocupação com o fazer história na perspectiva cultural e com a escolha dos documentos a serem utilizados pelo pesquisador, bem como com o olhar sobre eles. Hunt (1992) aponta que os historiadores devem sempre ser críticos relativamente a seus documentos - e nisso residem os fundamentos do método histórico.

Este estudo vincula-se à perspectiva da História Cultural, que considera as práticas e as representações dos sujeitos como um modo de caracterizar os fenômenos sociais investigados (BURKE, 2005). As discussões em torno da História Cultural e da História da Educação, assinalam que a história da educação é 
[...] um campo de investigações em que se torna cada vez mais necessário dar visibilidade aos seus diferentes objetos: a escola, o professor, os alunos, materiais escolares; processos e formas de aprendizagem, entre tantos outros. Nesse sentido, também se torna cada vez mais necessário dar visibilidade aos procedimentos metodológicos e referenciais teóricos que produzem tais objetos como objetos da história cultural, política econômica e social. (VEIGA, 2008, p. 19).

Esse argumento, entende-se, está relacionado a uma problematização com relação ao rigor acadêmico da área das ciências humanas e corrobora a necessidade da discussão proposta, que procura, de acordo com a autora, visibilizar os procedimentos metodológicos e os referenciais teóricos que produzem tais objetos.

Com relação aos aspectos teóricos, para a discussão e a análise histórica dos objetos pesquisados, empregam-se aqui os conceitos de estratégia, tática e representação apresentados por Certeau (2011).

Ao tratar das limitações e das tensões encontradas nesse modo de fazer história, entende-se que, se estamos em busca de traçar uma postura e uma intenção partilhada no sentido de traduzir o mundo a partir da cultura, é preciso descobrir os fios, tecer a trama geral do contexto e prestar atenção em elementos recorrentes, bem como, talvez, relevar as diferenças entre os autores - o que, sem dúvida, é um risco (PESAVENTO, 2008). Na constituição dessa trama a utilização de impressos foi uma das possibilidades de construção de uma inteligibilidade histórica.

Para a discussão do uso do jornal como documento, os estudos de Chartier (2002) abordam a história da leitura e seus impressos e Luca (2005) discute o uso específico do jornal como material historiográfico. Esses autores expressam a preocupação com o fazer da história nessa perspectiva cultural, com a forma de escolha dos documentos pelo pesquisador e a perspectiva de análise sobre esses registros.

Os autores citados ainda sinalizam para a importância de se ter um olhar atento, de que não há uma verdade única a ser expressa a partir dos materiais analisados. A luz desses autores essas 
preocupações se mantêm presentes na análise proposta por essa investigação.

Apresentamos ferramentas utilizadas e formas de análises construídas ao longo do processo de investigação. Foram essas as análises possíveis no processo de entender o contexto de criação da Instituição e as repercussões para os dias atuais.

Alves e Menezes (2012) e Faria Filho (2010) discutem o campo da educação no governo Juscelino Kubitschek (JK), suas reflexões foram importantes para a compreensão da empiria selecionada, pois abordam a educação desde 1960 até 2000. Com suas análises os autores permitem um aprofundamento dos conhecimentos sobre o ensino profissionalizante no período em questão.

Há muitas implicações no que diz respeito ao desenvolvimento do ensino industrial no Brasil; dentre elas, a necessidade da industrialização na década de 1930, o "Plano de Metas" e o objetivo dos "50 anos em 5", proclamado no governo de JK, até chegar-se à intervenção militar de 1964. Batista e Lima (2011, p. 44) afirmam que:

[...] desde o surgimento do ensino brasileiro, houve um modelo educacional destinado aos trabalhadores, que receberam uma formação técnica especifica para o trabalho assalariado, alienado e nos padrões determinados pelo Estado. Assim como houve outro modelo educacional destinado à elite, que recebeu uma formação abrangente e adequada para assumir o papel de dirigente da sociedade capitalista, vigente desde o século XVIII, até os dias atuais.

Entender a conjuntura do ensino profissional brasileiro, bem como as mudanças na legislação articuladas às análises e teorias de autores que já haviam investigado a temática, foi determinante para o entendimento do que ocorreu no município de Novo Hamburgo e daquilo que levou à efetiva instalação da Liberato.

Cotejar os acontecimentos de Novo Hamburgo, a criação de uma instituição nesse município com os acontecimentos do País é uma forma de articular o local ao global, não permitindo que se entenda o objeto de análise como uma ilha de singularidades, como 
apologia às pequenas diferenças. Embora a pesquisa se dê em nível micro, entende-se, ao contrário, que os acontecimentos regionais, em determinados aspectos, estão intimamente vinculados às políticas de um governo em nível nacional.

Para analisar o período de idealização da escola, foram selecionados documentos institucionais, entre os quais se destaca um histórico da Instituição e artigos dos periódicos locais: "Jornal O 5 de Abril" (JO) e "Jornal NH" (JN) ${ }^{5}$. Assim, os documentos são compostos por todos os exemplares do "JO", publicados entre 1956 e 1959 e, todos os do "JN" de 1960 a $1967^{6}$.

O método utilizado para identificar os jornais com as notícias que interessavam foi realizado da seguinte forma: identificação, em chamadas de matérias do jornal no tomo analisado, da presença das expressões "escola técnica", "Liberato", "Ensino técnico" e "Fundação Liberato"; fotografia da capa do jornal, que identificava a edição e a página da matéria; e por fim, leitura da matéria em si. Coletaram-se 49 artigos, nominando-se cada foto com um código, ano e número correspondentes. $\mathrm{O}$ número $\left(\mathrm{n}^{\circ}\right)$ da foto correspondia à localização do artigo no ano, pois, a cada ano, poderia haver mais de um artigo.

Com essa codificação, foi possível produzir um quadro para cada jornal, que continha as seguintes informações:

Quadro1 - Exemplo da catalogação adotada para registro dos artigos encontrados

\begin{tabular}{|c|c|c|c|c|c|}
\hline Ano & Título & Arq. & Pág. & Obs.: & Tomo \\
\hline 1956 & $\begin{array}{l}\text { Cogita-se dotar Novo } \\
\text { Hamburgo de uma Escola } \\
\text { Técnico-Profissional }\end{array}$ & $\begin{array}{l}11 \\
12 \\
13 \\
14\end{array}$ & Capa & $12 / 10 / 56$ & $\begin{array}{l}\text { Jan - } \\
\text { dez } \\
1956\end{array}$ \\
\hline
\end{tabular}

Fonte: Elaboração das autoras.

\footnotetext{
${ }^{5}$ No decorrer do texto, serão utilizadas as seguintes siglas: JN, para o Jornal NH, e JO, para o Jornal $\mathrm{O} 5$ de Abril. Também serão utilizadas as siglas $\mathrm{NH}$, para o município de Novo Hamburgo, e RS, para o Estado do Rio Grande do Sul.

6 Os jornais encontravam-se no Arquivo Municipal de Novo Hamburgo, onde são encadernados em tomos por semestre de cada ano.
} 
Após a seleção dos materiais obtidos, iniciou-se a análise dos artigos, que foram lidos cuidadosamente. Na leitura, procurou-se identificar excertos importantes que trouxessem notícias sobre a instituição. Esses artigo reunidos possibilitaram acompanhar e descrever movimentos dos primeiros tempos da Fundação Liberato, esse aspecto gerou outras tabelas, que possibilitaram as análises.

Os documentos encontrados na Liberato dão conta de apresentar as leis e os decretos que possibilitaram a desapropriação do terreno. O Decreto Municipal 4/57 e a assinatura do convênio em primeira instância, no munícipio de Novo Hamburgo, pelo Prefeito Carlos Armando Koch, pelo Governador Ildo Meneghetti e, representando a União, pelo Ministro da Educação e Cultura, Clovis Salgado, foram determinantes nesse processo de criação. A oficialização do convênio deu-se com sua publicação no Diário Oficial do Estado - Decreto Legislativo n. 941, de 17 de julho de 1957.

Esses documentos não dão visibilidade, obviamente, aos movimentos políticos e sociais que permitiriam a análise das representações da comunidade para com essa escola; isso foi possível pelo uso dos jornais, que são documentos fundamentais para a compreensão dos contextos políticos sociais e dos discursos preponderantes em tempos pretéritos.

Sabe-se que as intenções expressas na imprensa, como em outros documentos, não são isentas de influência política. É o que sugerem as primeiras análises desses periódicos. Quanto ao uso do jornal e a suas limitações, os autores alertam sobre os cuidados com o uso dessa fonte: "o uso instrumental e ingênuo que tomava os periódicos como meros receptáculos de informações a serem selecionadas, extraídas e utilizadas ao bel prazer do pesquisador. Daí o amplo rol de prescrições que convidavam à prudência" (LUCA, 2005, p. 116).

Diante desse convite à prudência, pode-se analisar os diferentes aspectos que emergiram dessas leituras e que possibilitaram tecer a trama geral da história do início da Liberato, sob uma perspectiva cultural. 


\title{
AS JUSTIFICATIVAS PARA A CRIAÇÃO DA ESCOLA TÉCNICA EM NH: um caminho por meio de jornais
}

Em 12 de outubro de 1956, um artigo abordava a Liberato ao descrever a intenção de se instalar uma escola técnico-profissional em Novo Hamburgo; dele foram retiradas as primeiras informações sobre o que justificaria a instalação da Escola no munícipio.

A reportagem informa que o Sr. Hipólito Brum ${ }^{7}$, autor de um memorial enviado à Câmara Municipal de Novo Hamburgo, encabeçara um movimento para trazer a Novo Hamburgo a escola técnico-profissional, que o Governo Federal queria instalar próximo à Capital. Nesse memorial, constam as justificativas da petição à Câmara Municipal, e Hipólito reivindicava que tal escola fosse instalada em $\mathrm{NH}$. O artigo reproduz parte do memorial:

\begin{abstract}
Vamos procurar mostrar que não estamos impondo absurdo e sim pleiteando o reconhecimento de direitos. Ou não terá essa população trabalhadora e produtora de Novo Hamburgo o direito de possuir, com primazia no Estado, a Escola TécnicoProfissional? Ou não será exato, que somos a verdadeira cidade industrial, Manchester brasileira, o maior parque industrial, o maior contribuinte? ("O 5 de Abril", 1956, capa).
\end{abstract}

O artigo relata, ainda, o envio de um telegrama ao então Governador do RS, listando justificativas e solicitando que fosse instalada a instituição em $\mathrm{NH}$. Assinam o telegrama 43 pessoas, e nota-se que elas eram expressivas na comunidade hamburguense, pois incluíam prefeito, juízes de direito, advogados, presidentes de associações, de sindicatos e de partidos políticos, e ainda o médico do posto de saúde e o delegado de polícia.

Das razões levantadas para se instalar a escola na cidade, sobressaem-se três: 1) a contribuição de Novo Hamburgo aos cofres públicos pela produção do munícipio; 2) o fato de ser $\mathrm{NH}$ um centro

\footnotetext{
${ }^{4}$ Hipólito Brum era advogado na comarca de Novo Hamburgo e foi Promotor Público do município. Não foi possível concluir se já exercia a função de promotor à época da publicação do artigo.
} 
fabril do estado - uma cidade industrial; 3) a falta de mão de obra especializada na região para a continuidade da produção e o consequente progresso da industrialização, o que aumentaria a contribuição aos cofres públicos.

Sobre a primeira e a segunda razões, os estudos de Selbach ${ }^{8}$, esclarecem: "No reinado do couro, as fábricas de calçado faziam a cidade. Em pouco tempo, Novo Hamburgo passou à condição de maior contribuinte per capita dos cofres públicos." (SELBACH, 1999, p. 100). Novo Hamburgo era conhecida na época como "Courocap", "Industrial", "Manchester Brasileira" ou, simplesmente, "Capital Nacional do Calçado". Em 1954, era maior o número de indústrias do que de estabelecimentos comerciais: "403 indústrias contra 350 casas de comércio." (SELBACH, 1999, p. 100).

A terceira razão diz respeito à falta de mão de obra especializada para a continuidade da produção, o que não era exclusividade de NH. Conforme propõe Amorin (2013), ao longo da década de 1930, foram criados órgãos governamentais que tinham por objetivo incentivar e regulamentar o ensino profissional, e isso fez com que, dessa década em diante, o ensino profissional se constituísse como prioridade em algumas políticas governamentais. Amorim acrescenta:

Como se pode verificar, as atenções estão voltadas para o ensino profissional nesse momento, não somente pelas várias tentativas de organização e sistematização, mas, principalmente, pelo fato de o Brasil passar por um período de expansão industrial. (AMORIN, 2013, p. 127).

O incentivo ao ensino industrial sustenta-se por objetivos conhecidos, relacionados à dualidade da educação brasileira quanto ao tipo de formação para filhos de trabalhadores e para filhos da elite. Essas intenções perpassam os governos e suas políticas, sendo explicitamente percebidas em algumas ocasiões e, em outras, nem

\footnotetext{
${ }^{8}$ Trata-se de uma dissertação de mestrado defendida no Programa de Pós-Graduação em Planejamento Urbano e Regional da UFRGS. Neste estudo, o autor analisa espaços urbanos de Novo Hamburgo, na intenção de entender o processo de urbanização da cidade.
} 
tanto. Amorim (2013) chama a atenção para essas intenções também no governo Vargas e para o apoio recebido dos empresários a suas políticas: "Se a intenção do governo Vargas era o controle dos trabalhadores pela disciplina do trabalho, certamente teria todo o apoio por parte do empresariado." Assim, perpetuar-se-ia o que era destinado aos filhos das elites e o que era destinado aos filhos dos trabalhadores; dessa forma, os empresários viram, no ensino profissional, uma forma de direcionar "estratégias de paz social e racionalização do trabalho" (AMORIM, 2013, p.129).

Os empresários viram, no ensino profissionalizante, a oportunidade de dar continuidade às suas intenções. Como o governo tinha o desejo de implantação, mas não a disponibilidade de meios, nem a velocidade com que os industriais desejavam, no processo de implantação desse ensino. Desse modo os empresários encarregaram-se de realizar

[...] a formação mais aligeirada de operários para atender às demandas emergenciais do setor industrial, com o Senai, mas não abriu mão de que o governo federal mantivesse instituições de ensino para a formação de técnicos com uma formação mais completa e abrangente. (AMORIN, 2013, p. 129).

Nesse sentido, percebe-se que se desenvolve a ideia de instalar a escola em Novo Hamburgo, pois não seria uma formação "aligeirada" - o que vinha ao encontro dos anseios da comunidade hamburguense, principalmente dos empresários e de nomes expressivos da sociedade, que desejavam evolução na área industrial da região.

Outra justificativa, mais velada, foi apontada pelo presidente da Associação Comercial em seu discurso: [...] O governo vai gastar dinheiro em Novo Hamburgo, vai pagar professores, vai pagar as despesas de manutenção, enfim, vai fazer recircular dinheiro que já saiu daqui." (Jornal $O 5$ de Abril, 1957, capa). Então, o governo devia tal escola a Novo Hamburgo pela contribuição do município aos cofres públicos. 
Encontram-se nove artigos que fazem referências a essas motivações para que a escola fosse instalada, tanto no início das reivindicações de que Novo Hamburgo a recebesse, como nos momentos de indignação, manifestados nos artigos a respeito das paralisações das obras.

Perseguindo essas motivações e justificativas, a comunidade, por meio de seus representantes políticos e de pessoas influentes, conquista o direito de ter a tão pleiteada instalação da Escola Técnico-Profissional em Novo Hamburgo, no bairro Primavera.

A utilização de jornais como documentos históricos possibilitou a construção dessa narrativa sobretudo no que se refere ao contexto micro, relacionado as disputas políticas e sociais da sociedade de Novo Hamburgo na época estudada.

\section{ARTICULAÇÃO ENTRE AS POLÍTICAS NACIONAIS E A CONTINUIDADE DAS OBRAS PARA A CONSTRUÇÃO DE UMA ESCOLA TÉCNICA}

A luta pelo direito à instalação da escola no munícipio marcou apenas o início da mobilização pela Liberato. Levaram-se 10 anos de constantes reclamatórias da comunidade para que a escola se tornasse realidade. Segundo o convênio firmado para construção da escola, construí-la e equipá-la era encargo da União. Então, observase que a política nacional influenciou diretamente a construção da Instituição. Como o País passou, em sua governança, por uma fase conturbada, era de se esperar que investimentos fossem cortados e que a construção da escola fosse comprometida.

Para entender o contexto político do período em análise, elaborou-se o quadro 2, identificando quem eram os governantes, a fim de que fosse possível visualizar a fase política correspondente a cada artigo que clamava pela volta da construção e pelos diversos pedidos de intervenção política feitos por meio da imprensa e por ela noticiados. 
Quadro 2 - Governantes das três esferas administrativas em comparação com o andamento das obras na Fundação Escola Técnica Liberato Salzano Vieira da Cunha

\begin{tabular}{|c|c|c|c|c|}
\hline & $\mathrm{NH}$ & RS & BR & Liberato \\
\hline 1956 & \multirow{4}{*}{ 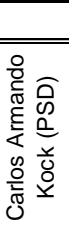 } & \multirow{3}{*}{$\begin{array}{c}\text { Ildo Meneghetti } \\
\text { (PSD)31/01/1955 a } \\
31 / 01 / 1959\end{array}$} & \multirow{4}{*}{$\begin{array}{l}\text { Juscelino Kubitschek (PSD) } \\
31 / 01 / 1956 \text { a } 31 / 01 / 1961\end{array}$} & \multirow{4}{*}{$\begin{array}{l}\text { Comunidade conquista instalação } \\
\text { em NH } \\
\text { Obras - concreto armado finalizado }\end{array}$} \\
\hline 1957 & & & & \\
\hline 1958 & & & & \\
\hline 1959 & & \multirow[t]{6}{*}{$\begin{array}{c}\text { Leonel de Moura } \\
\text { Brizola (PTB) } \\
31 / 01 / 1959 \text { até } \\
31 / 01 / 1963\end{array}$} & & \\
\hline 1961 & \multirow{5}{*}{ 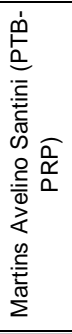 } & & $\begin{array}{|lcc|}\text { Jânio } & \text { Quadros } & \text { (PTN) } \\
31 / 01 / 1961 & \text { a } 25 / 08 / 1961 \\
\end{array}$ & \multirow[t]{4}{*}{ Obras - paralizadas } \\
\hline & & & $\begin{array}{|lll|}\text { Ranieri } & \text { Mazzilli } & \text { (PSD) } \\
\text { 25/08/1961 a 8/09/1961 } & \\
\end{array}$ & \\
\hline & & & \multirow[t]{4}{*}{$\begin{array}{c}\text { João Goulart (PTB) 08/09/1961 } \\
\text { a 31/03/1964 }\end{array}$} & \\
\hline 1962 & & & & \\
\hline 1963 & & & & $\begin{array}{c}\text { Promessa de Liberação de verbas } \\
\text { Anunciado início das aulas em } \\
\text { MAR } 64\end{array}$ \\
\hline \multirow{3}{*}{1964} & \multirow{6}{*}{ 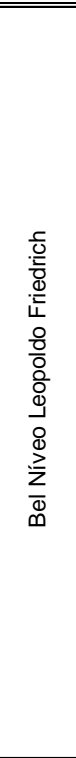 } & \multirow[t]{5}{*}{$\begin{array}{c}\text { Ildo Meneghetti } \\
\text { (PSD) 31.01.1963 / } \\
\text { 31.01.1967 }\end{array}$} & & $\begin{array}{c}\text { Ajuste no projeto original } \\
\text { diminuição de } 60000 \mathrm{~m}^{2} \text { para } \\
16000 \mathrm{~m}^{2}\end{array}$ \\
\hline & & & \begin{tabular}{|lll} 
Ranieri & Mazzilli \\
02/04/1964 a $15 / 04 / 1964$
\end{tabular} & \\
\hline & & & $\begin{array}{l}\text { Castelo Branco (ARENA) } \\
15 / 04 / 1964 \text { a } 15 / 03 / 1967\end{array}$ & $\begin{array}{c}\text { Obras - Reiniciam com liberação } \\
\text { de verbas esparsas }\end{array}$ \\
\hline \multirow[t]{3}{*}{1965} & & & & $\begin{array}{c}\text { Obras- em andamento anunciado } \\
\text { funcionamento para 1966, mas } \\
\text { paralizam na metade do ano. }\end{array}$ \\
\hline & & & & $\begin{array}{c}\text { Obras- reiniciadas } \\
\text { Anunciado financiamento do BID } \\
\text { Definido funcionamento em } 1967 \\
\text { somente do curso de química. } \\
\text { Entraves de legislação e } \\
\text { liberações do Estado. }\end{array}$ \\
\hline & & \begin{tabular}{|c} 
Walter Peracchi \\
Barcelos (ARENA) \\
31.01.1967 / \\
15.03 .1971
\end{tabular} & $\begin{array}{l}\text { Costa e Silva (ARENA) } \\
15 / 03 / 1967 \text { a } 31 / 08 / 69\end{array}$ & $\begin{array}{c}\text { Surge a Necessidade de virar } \\
\text { Fundação estadual - questões } \\
\text { legais. } \\
\text { AULA INAUGURAL EM } \\
\text { 12/04/1967. }\end{array}$ \\
\hline
\end{tabular}

Fonte: Elaboração das autoras.

O período aqui em questão leva a percorrer épocas distintas e importantes para a política nacional, envolvendo os anos que antecederam o golpe militar de 1964 e o próprio período do golpe. Conforme um dos artigos do Jornal $\mathrm{NH}$, esse período "já viu passar 
quatro presidentes da república, que foram JK, Jânio, Jango e Mazilli". (JORNAL NH, 1965, p.1).

Na década de 1950, o Brasil sofria com a crise econômica e as guerras mundiais; além disso, as mudanças no cenário internacional refletiam-se na economia. Quando Juscelino Kubitschek assume a presidência, seu ideal, por meio do Plano de Metas, era mudar a relação entre o Estado e a economia do país, visando a buscar, em tempo recorde, o desenvolvimento do Brasil, como afirma Alves e Menezes? (2012). Esse autor defende que o impulso dado à política nacional voltava-se a fomentar três setores fundamentais: indústria, modernização da agricultura e educação.

Por sua vez, a gestão de Kubitschek estaria fortemente voltada a empreender a vitória do país contra a barreira do analfabetismo e despreparação intelectual e técnica que se impunha aos objetivos de alta e veloz modernização pelo país então almejados, buscando, por meio do plano de metas, mais precisamente quanto à educação, a meta de número 30 do plano, que visava dotar o país de uma infra e superestrutura industrial, modificando a conjuntura econômica do país, que devia ser acompanhada de uma bem engendrada infraestrutura educacional. (ALVES; MENEZES, 2012, p. 3).

Estudar as intenções desse governo para com o País e, por consequência, aquilo que admitia ser necessário para alcançar seus objetivos contribui para o entendimento sobre os elementos que tornaram possível o convênio entre a União, o Estado e o Munícipio para que a Liberato fosse criada. Com a necessidade de o País desenvolver-se por meio da industrialização, seria coerente investir nessa formação; além disso, fazer isso na região Sul, na cidade de Novo Hamburgo, era também coerente, pois, na época, a cidade era um grande polo calçadista em expansão.

No quadro 2, percebe-se que, durante o governo JK, houve tencionamentos e disputas no processo de instalação da escola, o objetivo de construção que foi alcançado devido à mobilização política e social da comunidade. Nesse período, publicaram-se oito 
artigos, que davam conta de comunicar desde o andamento até o efetivo início das obras.

A edição do Jornal NH de 16 de abril de 1960, conforme a figura reproduzida a seguir, trouxe a primeira foto do andamento das obras, o que coincidiu com o último ano de governo JK. Confirma-se na edição de 04 de junho de 1965: "No ano de 1962, estava pronta a estrutura de concreto armado, quando a obra sofreu uma paralisação que durou até 1963". O período indicado coincide com o conturbado e curto mandato de Jânio Quadros na Presidência da República, que culmina com sua renúncia.

Figura 1 - Reportagem sobre a construção da Liberato

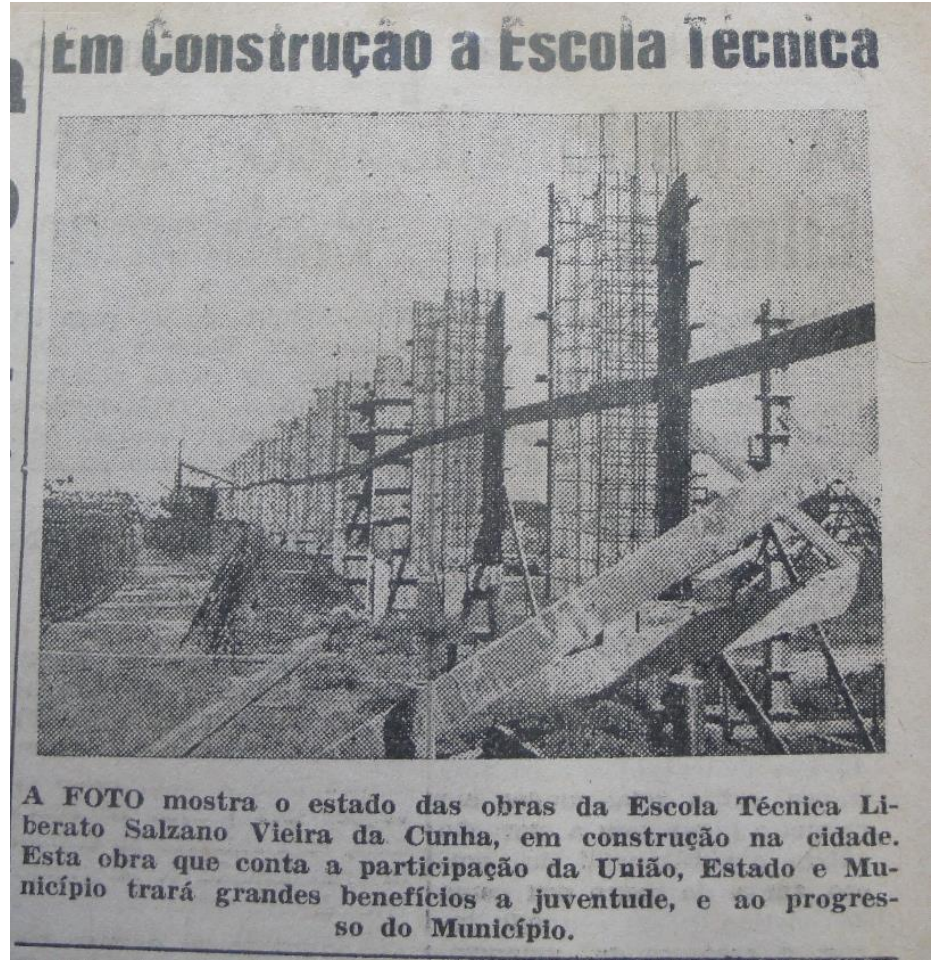

Fonte: Jornal NH, 16/04/1960.

As percepções acerca desse momento histórico indicam que há, por parte do governo, um contexto de indefinições e de disputas federais significativas. Os ministros militares não aceitam a posse do 
vice-presidente João Goulart, que também havia sido vice de Juscelino Kubitschek, e o País passa a ser governando sob grande pressão, como argumenta Palma Filho:

Os ministros militares resistem em princípio, mas acabam por ceder com a condição de que o Presidente da República tivesse os seus poderes presidenciais de chefe do Poder Executivo diminuídos. A saída foi o Congresso Nacional aprovar a emenda parlamentarista. Jango, como era conhecido João Goulart, político conciliador, aceita. Porém, não desiste do regime presidencialista, como, aliás, é da tradição republicana brasileira. (PALMA FILHO, 2010, p. 4).

Os anos de 1961 a 1963 marcam o período que mais apresentou matérias publicadas: 17 artigos que envolviam a instalação da Escola Técnica em $\mathrm{NH}$, vários deles noticiando movimentações de reivindicação de verbas, indicando a paralisação das obras, apelando a alguns políticos ligados à região, que ou vieram visitar as obras, ou foram procurados pela comunidade hamburguense para darem apoio à causa.

Em 31 de janeiro de 1961, Jânio Quadros inicia seu mandato, e renuncia em 25 de agosto. Nesse período, em 08 de abril de 1961, é publicado um artigo, no JN, intitulado "400 Milhões para Escola Técnica". Esse artigo noticia a visita do Deputado Federal Tarso Dutra e do Deputado Estadual Ariosto Jaeger, que se mostram impressionados com o tamanho da obra e informam que, no congresso dos governadores em Santa Catarina9, o Governador Leonel Brizola teria levado a conhecimento do Presidente Jânio Quadros a necessidade de verbas para a escola. Nesse encontro, teria sido designado às obras o montante de 200 milhões de cruzeiros para 1962 e de 200 milhões de cruzeiros para 1963.

Observa-se que, no início do governo de Jânio Quadros, quando este é informado da obra - e, provavelmente, bem

\footnotetext{
${ }^{9}$ Esse primeiro congresso dos governadores é hoje denominado Sistema CODESUL-BRDE (Conselho de Desenvolvimento e Integração Sul do Banco Regional de Desenvolvimento do Extremo Sul) e destaca-se como importante instituição regional criada para fortalecer o desenvolvimento do sul do País.
} 
influenciado pelo conclave dos governadores e pelos deputados que estavam envolvidos com a causa da Liberato -o então Presidente foi convencido da importância da liberação das verbas; mas, como não permaneceu no governo, a verba não chegou, e a obra acabou por ficar à mercê de nova batalha dos políticos e da comunidade para encontrar a brecha necessária no sentido de persuadir o novo governo.

Essa batalha de convencimento da importância da construção da escola direcionada ao governo do Presidente João Goulart pode ser percebida pela enxurrada de artigos publicados no ano de 1962 , em que diversos políticos novamente aparecem em cena. Naquele ano, o jornal publica 15 artigos que mencionam, direta ou indiretamente, as obras paralisadas da Escola Técnica. O JN empenha-se em acompanhar e registrar os movimentos realizados pelo prefeito em busca de verbas para algumas questões prioritárias ao munícipio, dentre as quais estão, como segunda prioridade, a Escola Liberato Salzano. Dos 15 artigos, cinco referem-se à Liberato indiretamente. Um desses tem a seguinte chamada: "Com Destino ao Rio de Janeiro e Brasília Viajou a Diretoria do Dep. Da Fazenda da Municipalidade: Festa do Calçado, Hospital Operário, Escola Técnica e Aparelho de Raio-X, motivos que determinaram a viagem - Jango poderá ser visitado".

Há várias promessas durante esse governo, mas só se percebe movimentação real nas obras ao final de 1963 e no início de 1964, ainda no governo do Presidente João Goulart. Nesse período, realizase um estudo para redução do projeto inicial, de $60.000 \mathrm{~m}^{2}$ para $16.000 \mathrm{~m}^{2}$ (JORNAL NH, 1961).

As informações apresentadas levam a inferir que, a cada mudança de governo federal, era necessária uma movimentação da comunidade hamburguense para conscientizar as governanças da importância da escola para a região, por isso a necessidade de lutar por ela e não desistir. A cada troca de governo, havia o tempo de movimentação (procura dos políticos), o tempo de conscientização (conversas e apresentação de justificativas) e o tempo de burocracia para liberação das verbas. Assim passaram-se os anos, até o início de 1964. 
Um movimento de embate e disputa não foi percebido na troca de governo, saída de Jango e a intervenção militar, o que pode advir de duas razões: primeiramente, o fato de que a obra já estava em andamento e de que seu projeto havia sido reduzido - portanto, era mais fácil sua finalização para o início do primeiro curso. A outra razão refere-se ao fato de que esse é o período em que aparecem os primeiros investimentos de órgãos internacionais, como o Banco Interamericano de Desenvolvimento (BID).

Mesmo assim, leva-se 3 anos para a aula inaugural da escola, no curso de Química. Inicia-se o curso com 67 alunos, 7 professores e 4 funcionários. O cargo de diretor era ocupado por Orlando Razzera, escolhido pelo governador do Estado a partir de uma lista indicada pelo Conselho Técnico da Escola. A Instituição, por questões legais, passa a ser uma Fundação do Estado, a fim de ter autonomia estatutária e atender ao previsto no convênio que regeu sua criação.

Inicia-se, nesse momento, a construção historiográfica de um itinerário que percorre o currículo e produz um discurso de excelência no ensino, no qual a pesquisa em sala de aula tem lugar de destaque.

\section{MITO FUNDADOR - FUNDAÇÃO LIBERATO COMO EXCELÊNCIA DE ENSINO}

Nos excertos analisados, é possível encontrar diversas expressões que indicam um conjunto de representações daquilo que se esperava que fosse a escola técnica. É uma promessa de solucionar os problemas de falta de mão de obra e de, com isso, auxiliar na resolução do problema do desenvolvimento brasileiro pela industrialização, que, como visto, foi a saída adotada como política dos governos daquele período.

A comunidade, quando de sua manifestação pela instalação da escola, tinha como intenção dar continuidade à expansão da industrialização da região, o que a imprensa registra em diversas ocasiões. Observem-se os títulos de alguns artigos: maio de 1959: "Em Novo Hamburgo uma das maiores Escolas Técnicas do Continente"; abril de 1962: "Paralisada a construção da escola técnica, uma obra monumental em NH"; outubro de 1962: "Liberato Salzano: um monumento abandonado". 
O conteúdo dos artigos leva a observar também a existência de elementos que remetem às reflexões de Chauí (2001), quando aborda o mito fundador: "Um mito fundador é aquele que não cessa de encontrar novos meios para exprimir-se, novas linguagens, novos valores e ideias, de tal modo que, quanto mais parece ser outra coisa, tanto mais é a repetição de si mesmo" (CHAUÍ, 2000, p. 4)

Essa repetição foi percebida ao longo do período analisado, como demonstrado pelos títulos citados e pelos excertos abaixo: "Estabelecimento especializado [...]" (JORNAL O 5 DE ABRIL, 19/04/1956, p.1); "A nova geração verá o nascimento da Escola Técnica Profissional como um farol - abrindo caminho certo [...]" para o porto seguro do conhecimento" (JN, 16/04/1960, p. s/n); "Representa aquela obra, algo de tudo, altamente importante, monumental, gigantesco e sobremaneira o maior desenvolvimento de nossa cidade, no aspecto técnico científico" (JN, 06/01/1962, p. 5).

Este último título, em específico, permite uma agenda de análise futura que está relacionada a representações produzidas pela comunidade no que diz respeito à importância dessa escola. Para isso, é importante considerar o fato de que, ao longo do seu percurso como instituição, produziu-se o enunciado de "ser científica", que vai se organizando antes de sua existência física. É um indício da fundação do mito que leva a escola a trabalhar com a pesquisa e que, hoje, torna a entidade conhecida por sua excelência na formação técnica profissional no Brasil.

Essa excelência tem como mote a construção de uma cultura escolar que introduziu, ao longo do percurso de funcionamento da Instituição, o incentivo à pesquisa em sala de aula como prática curricular, bem como a Metodologia da Pesquisa como disciplina obrigatória na graduação, com a intenção de, entre outras coisas, desenvolver o ensino técnico.

A análise do processo de implementação da pesquisa em nível secundário permite compreender esse espaço e a produção de uma pedagogia escolar que constrói, ao longo do tempo, determinado ethos institucional.

Para pensar o que se denomina de ethos, é fundamental entender que ele está vinculado àquilo que Julia (2001) denomina de cultura escolar. $\mathrm{O}$ autor postula que a cultura escolar está relacionada 
às práticas cotidianas, às normas institucionais que definem o que e como determinadas condutas serão produzidas e transmitidas, o que gera uma incorporação de determinados comportamentos.

O processo histórico aqui explicitado é o reavivamento de uma memória coletiva que permite a continuidade de uma ação, no sentido de compreender a Liberato nas suas singularidades, no entendimento de seu ethos, e, ainda, com vistas a ampliar e aprofundar a compreensão de sua relação com a comunidade.

\section{CONSIDERAÇÕES FINAIS}

Magalhães (2004) aborda a necessidade de se estudar representações e apropriações realizadas no meio escolar para que se analise a constituição das instituições escolares, o que só é possível por meio de um estudo completo, em que também se leva em conta os "produtos materiais e simbólicos" da instituição.

Iniciar esta pesquisa tentando entender o que a Liberato representou para a comunidade, mesmo antes de existir fisicamente, é fundamental para a continuidade do estudo, pois percebe-se que parte do ato de historiar a "cultura institucional" consiste em estudar a apropriação por transferência que os sujeitos fazem de seus "saberes, valores, capacidades, técnicas, atitudes, desequilibrando e ampliando seu repertório cognitivo em novos contextos" (MAGALHÃES, 2004, p. 118). Desse modo, descrever e entender o que se pensava sobre a escola, ao longo daqueles dez anos de construção, e que representações foram produzidas para aquela localidade parece essencial para estabelecer sentidos com relação aos produtos materiais e simbólicos dessa comunidade escolar.

Encontraram-se, até aqui, indícios da existência de um mito fundador, mesmo antes da existência física da instituição, em que se estabelecia uma promessa da instalação da maior e melhor escola técnica da região. Isso é percebido nas inúmeras manchetes do jornal, que indicavam a grandiosidade da futura entidade. Diversas foram as representações e práticas percebidas na comunidade hamburguense para que a promessa de futuro vindouro se concretizasse a partir da escola técnica. 
De modo geral, este estudo permitiu visibilizar como ocorreu a mudanças das políticas governamentais ao longo da construção da Liberato, desde os níveis mais amplos até o nível micro da fundação desta escola no período investigado. Permitiu também perceber o envolvimento, em certa medida, da comunidade em virtude do desejo de ter essa instituição na região. Por meio dela, vislumbravase um progresso perpetuado: com as representações de que o ensino técnico-profissional daria condições aos trabalhadores de obterem o conhecimento necessário para o desenvolvimento da indústria, a escola faria a diferença na formação "técnico-científica" desses trabalhadores.

\section{REFERÊNCIAS}

ALVES, T. V.; MENEZES, A. C. Educação Brasileira em Debate: 19561960. In: Encontro Regional da ANPUH - Rio, 15., Rio de Janeiro. Anais [...] Rio de Janeiro: ANPUH, 2012. Disponível em: http://zip.net/bmrwjk. Acesso em: 04 jul. 2015.

AMORIN, M. L. Exigência para o Desenvolvimento das Nossas Indústrias: O Ensino Técnico no Contexto da Lei Orgânica do Ensino Industrial. História da Educação, Porto Alegre, v. 7, n. 41, p. 123-138, 2013.

BATISTA, U. A.; LIMA, M. F. Considerações sobre a trajetória histórica da formação profissional no Brasil de 1940 a 1990. História da Educação, Porto Alegre, v. 11, n. 1, p. 35-47, set./dez. 2011.

BURKE, P. O que é História Cultural? Rio de Janeiro: Jorge Zahar, 2005.

CERTEAU, M. A Escrita da História. Rio de Janeiro: Forense, 2011.

CHARTIER, R. À Beira da Falésia. Porto Alegre: Ed. Universidade, 2002.

CHAUÍ, M. Brasil: Mito Fundador e Sociedade Autoritária. São Paulo: Fundação Perseu Abramo, 2000.

FILHO, J. C. P. A Educação Brasileira no período de 1960-2000. In: FILHO, J. C. P. Caderno de Formação- Formação de Professores - 
Educação, Cultura e Desenvolvimento. São Paulo: Cultura Acadêmica, 2010.

HUNT, L. A Nova História Cultural. São Paulo: Martins Fontes, 1992. JULIA, D. A cultura escolar como objeto histórico. Revista Brasileira de História de Educação, Maringá, n. 1, p. 9-44, jan./jun. 2001.

LENSKI, G. Human Societies: An Introduction to Macrosociology. New York: McGRaw-Hill, 1974.

LUCA, T. R. História dos, nos e por meio dos periódicos. In: PINSKY, C. B. (org.) Fontes históricas. São Paulo: Contexto, 2005.

MAGALHÃES, J. P. Tecendo Nexos: história das instituições educativas. Bragança Paulista: Editora Universitária São Francisco, 2004.

PALMA FILHO, J. C. Caderno de Formação. Formação de Professores - Educação Cultura e Desenvolvimento. São Paulo: Cultura Acadêmica, 2010.

PESAVENTO, S. J. História \& História Cultural. Belo Horizonte: Autêntica, 2008.

SELBACH, J. F. Novo Hamburgo 1927-1997: os espaços de sociabilidade na gangorra da modernidade. 1999. 370 f. Dissertação (Mestrado em Planejamento Urbano) - Universidade Federal do Rio Grande do Sul, Porto Alegre, 1999.

VEIGA, C. G. História Política e História da Educação. In: FONSECA, T. N. L.; VEIGA, C. G. História e Historiografia da Educação no Brasil. Belo Horizonte: Autêntica, 2008. p. 13-47.

VEYNE. P. Como se escreve a história e como Foucault revoluciona a História. Brasília: UNB, 2014.

Submetido em: Junho/ 2019.

Aceito em: Dezembro/ 2019. 